\title{
Oncoplastic Techniques for Surgical Management of Inner Half Breast Cancer
}

\author{
Elmessiry M.M, Abo Alnagah G.M, Elhosseiny M.A, Osman M.H \\ Department of General Surgery, Alexandria University, Egypt
}

For decades women with breast cancer were offered two surgical options: small lesions were treated with lumpectomy and radiotherapy (breast conserving therapy) and large tumors by mastectomy. Oncoplastic surgery (OPS) has emerged with the concept of applying plastic reconstructive techniques to reshape the breast after conservative resection to allow wide excision without compromising the natural shape of the breast. In the current study 60 female patients with operable breast cancer in inner half fit for BCS (T1\&T2) were treated by various oncoplastic techniques. The mean age was $44.40 \pm 9.83$ years, 15 patients had lower inner quadrant tumors $(25.0 \%), 45$ patients $(75 \%)$ had upper inner tumors. Round block technique was used in 18 cases $(30.0 \%)$, level I oncoplastic technique in 9 cases $(15 \%)$, superior pedicle reduction mammoplasty in 6 case (10\%), inferior pedicle reduction mammoplasty in 6 cases $(10 \%)$, v mammoplasty in 6 case (10\%), volume replacement by mini LD flap in 6 cases (10\%), fish hook rotational flap in 3 case (5\%) and batwing mastopexy in 3 case (5\%). The rate of complications was $20 \%$ and patients' satisfaction score was $4.2 \pm 0.87$. Local re $\neg$ currence rate was $3.3 \%$ in 24 months follow-up period.

Key words: Inner half, Breast cancer, Oncoplastic surgery, Surgical, Cosmetic \& Oncological Outcomes.

\section{Introduction}

The shift from radical surgical ablation to conserving treatment for breast cancer was actually led by radiotherapists with surgical intervention being added much later. For small $(2 \mathrm{~cm})$ and nodenegative tumors, however, Veronese et al deserve credit for the first randomized trial proving safe breast conserving surgery. ${ }^{1}$ Further studies, with larger $(4 \mathrm{~cm})$ tumors, confirmed that equivalent overall and disease-free survival to mastectomy could be produced by tumorectomy combined with radiotherapy: this has come to be known as "breastconserving therapy".2

Breast-conserving surgery is an excellent option for women who choose it, providing it can be performed without compromising the effectiveness of treatment whilst achieving an acceptable cosmetic result. The measurable outcomes of breast-conserving surgery are survival, local recurrence rates, cosmoses and patient satisfaction. Any assessment of treatment by breast-conserving surgery should report these outcomes for meaningful interpretation of results. ${ }^{3}$ Oncoplastic breast surgery consists of various techniques that allow for an excision with a wider margin and a simultaneous enhancement of cosmetic sequelae, making it an ideal breast cancer surgery. ${ }^{4,5} \mathrm{~A} 2008$ audit of a specialist breast practice reported that breast reconstruction and oncoplastic operations accounted for $28 \%$ of all breast-cancer related procedures, indicating a rising utilization of oncoplastic breast surgery. The surgical techniques used in oncoplastic breast surgery in the setting of breast conservation can be largely divided in two categories: volume displacement (VD) and volume replacement (VR). Appropriate technique is chosen based on patient and tumor characteristics, as the outcomes of the surgery may depend on the type of technique. ${ }^{6}$

\section{Patients and methods}

This prospective study was conducted between November 2015 and September 2018 on sixty female patients with operable breast cancer in inner half (upper and lower inner quadrants) fit for BCS (T1 \& T2) admitted to the oncology department, Alexandria university, Egypt.

All studied patients signed an informed consent and subjected to complete history taking, complete physical examination and breast examination including breast masses, nipple and areola and axilla. Routine laboratory investigations were done. Breast ultrasound and mammograms were routinely done. Pre-operative pathological assessment was done using fine needle aspiration cytology (FNAC) or needle core biopsy.

\section{A. Patients with upper inner quadrant tumors were treated by one of the following oncoplastic techniques:}

- Level I oncoplastic technique: If less than $20 \%$ of the breast volume is excised. It's based on dual-plane undermining, including the nipple- areola complex (NAC), and NAC recentralization if nipple deviation is anticipated.

- Round block technique: Making two concentric periareolar incisions, followed by de-epithelialization of the intervening skin. The outer edge of de-epithelialization is incised and the entire skin envelope is undermined in a similar manner to performing a mastectomy. Wide excision of the tumor and surrounding tissue is performed from the subcutaneous 
plane down to the pectoralis fascia. The medial and lateral glandular flap are then mobilized off the pectoralis muscle and sutured together.?

- Batwing mastopexy: Two closely similar halfcircle incisions are made with angled wings to each side of the areola. Full-thickness excision is undertaken and the fibro-glandular tissue is advanced to close the subsequent defect. ${ }^{8}$

- Inferior pedicle reduction mammoplasty: It begins with de-epithelialization of the area surrounding the NAC. The NAC is then dissected away from the underlying breast tissue on an inferior dermo-glandular pedicle. The inframammary incision is then completed, followed by wide undermining of the breast tissue off the pectoralis fascia.

- Volume replacement by mini LD flap: Latissimus dorsi (LD) myocutaneous flaps or mini LD flap are used to fill the defects after excision of relatively large tumor in smallmedium sized breast (cup size A-B) or if the patient refused the decrease in her breast size via tissue displacement techniques. ${ }^{9}$

Patients with lower inner quadrant tumors were treated by one of the following oncoplastic techniques:

- Lower inner quadrant v-mammoplasty: By excising a pyramidal section of gland, with its base located in the sub-mammary fold and apex at the border of the areola. The section is removed, including the skin attached to the gland down to the pectoralis fascia. The sub-mammary fold is then incised, from the resection site to the anterior axillary line to allow adequate rotation of the remaining gland into the defect. The lower pole of the breast is entirely undermined from the pectoralis muscle and transferred medially to fill the defect. The NAC is then recentralized. ${ }^{10}$

- Fish-hook inferior rotational flap: Fishhook-shaped skin incision line is designed. The incision is marked from an axillary site to the tumor, about $2-3 \mathrm{~cm}$ below the skin crease of the infra-mammary fold. The tumor was removed with at least $2 \mathrm{~cm}$ margins for oncologic safety. A superior-based dermo-glandular tissue flap was mobilized off the pectoralis major muscle, taking into consideration the blood supply to the flap and remnant breast. The dermo-glandular flap was then rotated to fill the defect and the lower abdominal flap was dissected downward, enough to be pulled up. ${ }^{11}$

- Superior pedicle reduction mammoplasty: Begins with de-epithelialization of the area surrounding the NAC. The NAC is then dissected away from the underlying breast tissue on a superior dermo-glandular pedicle. The inframammary incision is then completed, followed by wide undermining of the breast tissue off the pectoralis fascia. The undermining starts inferiorly and then proceeds superiorly beneath the tumor while encompassing the medial and lateral aspects of the breast as well as the NAC. The tumor is removed en bloc with a large margin of normal breast tissue and overlying skin as determined by the preoperative drawings. ${ }^{12,13}$

- The choice of oncoplastic techniques depend on tumor size and location in relation to breast size and density. Displacement oncoplastic techniques are preferable in medium sized breast, while breast re-placement oncoplastic techniques were preferred when a large excised volume was anticipated in small sized breasts. Reduction mammoplasty techniques are the preferred option in large sized breasts. These techniques can facilitate the delivery of postoperative radiotherapy, particularly in women with macromastia, by reducing the size of the breast. In addition, they do not affect clinical and radiologic follow-up. ${ }^{13}$

\section{Results}

Demographic data: The age ranged from 28 to 61 years (mean $44.40 \pm 9.83$ years and median 43 years). Family history of breast cancer in the first or the second degree relatives was positive in only 12 patients (20.0\%). 33 patients were premenopausal $(55.0 \%)$ and 27 patients were postmenopausal $(45.0 \%)$. All of patients were multiparous $(100 \%)$. 36 patients $(60 \%)$ gave history of using oral contraceptive pills while the remaining patients (40\%) gave no history of oral contraceptive pills. (Table 1).

Table 1: Demographic data

\begin{tabular}{lll}
\hline & No. & \% \\
\hline Age (years) & & \\
$<30$ & 3 & 5.0 \\
$30-40$ & 18 & 30.0 \\
$41-50$ & 21 & 35.0 \\
$\quad>50$ & 18 & 30.0 \\
Family history & & \\
$\quad$ Negative & 48 & 80.0 \\
$\quad$ Positive & 12 & 20 \\
Menstrual history & & \\
$\quad$ Premenopausal & 33 & 55.0 \\
$\quad$ Postmenopausal & 27 & 45.0 \\
Parity & & \\
$\quad$ Nulliparous & 0 & 0.0 \\
$\quad$ Multiparous & 60 & 100.0 \\
Oral contraceptive pills use & & \\
$\quad$ Positive & 36 & 60.0 \\
$\quad$ Negative & 24 & 40.0 \\
\hline
\end{tabular}


Breast examination: The tumor was in the left side in 45 cases (75\%) and in the right side in 15 cases (25\%). Bra cup size was used to assess the size of the breast 6 patients $(10 \%)$ had moderate breast size (Cup B), 30 patients (50\%) had large breast size (Cup C), while 24 patients (40\%) had larger breast size (Cup D or larger). 6 patients $(10.0 \%)$ didn't have ptosis (the entire breast, including the NAC, liess above the level of the inframammary crease). None had mild ptosis (the nipple lies at the level of the infra-mammary crease), 21 patients $(35.0 \%)$ had moderate ptosis (the nipple lies below the level of the infra-mammary crease but remained above the lower contour of the breast gland), and 30 patients (50\%) had severe ptosis (the nipple liess below the infra-mammary crease and along the lower contour of the breast). 12 patients (20\%) experienced substantial asymmetry of both breasts pre-operative. (Table 2).

Table 2: Breast examination

\begin{tabular}{lll}
\hline & No. & $\%$ \\
\hline Right & 15 & 25.0 \\
Left & 45 & 75.0 \\
Breast size & & \\
A & 0 & 0.0 \\
B & 6 & 10.0 \\
C & 30 & 50.0 \\
D & 24 & 40.0 \\
Ptosis & & \\
No & 6 & 10.0 \\
Minor & 6 & 10.0 \\
Moderate & 15 & 25.0 \\
Severe & 33 & 55.0 \\
Asymmetry & & \\
Negative & 48 & 80.0 \\
Positive & 12 & 20.0 \\
\hline
\end{tabular}

Characteristics of the primary tumor: 15 patients had lower inner quadrant tumors (25.0\%), 45 patients $(75 \%)$ had upper inner tumors. The tumor size ranged from 1 to $4.6 \mathrm{~cm}$ (2.74 \pm 0.98 $\mathrm{cm} .33$ patients (55\%) had enlarged ipsilateral lymph nodes either clinically or on imaging (N1). 45 patients had stage II disease $(75.0 \%)$, while only 15 patients $(25.0 \%)$ had stage I disease (according to TNM staging system). (Table 3 ).

Table 3: Characteristics of the primary tumor

\begin{tabular}{|c|c|c|}
\hline Tumor & No. & $\%$ \\
\hline \multicolumn{3}{|l|}{ Site } \\
\hline Upper inner & 45 & 75.0 \\
\hline Lower inner & 15 & 25.0 \\
\hline \multicolumn{3}{|l|}{ Size } \\
\hline Min. - Max. & \multicolumn{2}{|c|}{$1.0-4.6$} \\
\hline Mean \pm SD & \multicolumn{2}{|c|}{$2.74 \pm 0.98$} \\
\hline Median & \multicolumn{2}{|c|}{2.30} \\
\hline \multicolumn{3}{|l|}{ Lymph node } \\
\hline Negative & 27 & 45.0 \\
\hline Positive & 33 & 55.0 \\
\hline \multicolumn{3}{|c|}{ Stage of the disease } \\
\hline I & 21 & 35.0 \\
\hline II & 39 & 65.0 \\
\hline
\end{tabular}

Surgical technique: In 45 cases with upper inner tumor we used level I oncoplastic technique in 9 cases $(15 \%)$, round block technique in 18 cases $(30.0 \%)$, batwing mastopexy in 6 cases (10\%), inferior pedicle reduction mammoplasty in 6 cases $(10 \%)$, and volume replacement by mini LD flap in 6 cases $(10 \%)$. While in 15 cases with lower inner tumor we used v-mammoplasty in 6 cases $(10 \%)$, fish hook rotational flap in 3 cases (5\%) and superior pedicle reduction mammoplasty in 6 cases $(10 \%)$. (Table 4).

Table 4: Surgical technique

\begin{tabular}{llcc}
\hline Surgical technique & No. & \% \\
\hline Upper inner: & Level 1 oncoplastic & 9 & 15.0 \\
& Round block & 18 & 30.0 \\
& Batwing mastopexy & 6 & 10.0 \\
& Inferior pedicle mammoplasty & 6 & 10.0 \\
& LD flap & 6 & 10.0 \\
Lower inner: & V mammoplasty & 6 & 10.0 \\
& Fish hook rotational flap & 3 & 5.0 \\
& Superior pedicle mammoplasty & 6 & 10.0
\end{tabular}


Postoperative complications: Postoperative complications occurred in 12 patients $(20 \%) ; 3$ case had skin necrosis (5\%), 3 case had seroma (5\%), 4 case had superficial infection (6.7\%) which resolved in two weeks of antibiotic therapy and 2 cases had wound dehiscence (3.3\%) and healed spontaneously by dressing and did not require any surgical intervention. (Table 5).

Table 5: Postoperative complications

\begin{tabular}{|c|c|c|c|c|c|}
\hline Surgical technique & No. & Skin necrosis & Seroma & $\begin{array}{c}\text { Wound } \\
\text { Dehiscence }\end{array}$ & $\begin{array}{l}\text { Superficial } \\
\text { Infection }\end{array}$ \\
\hline Upper inner: Level 1 oncoplastic & 9 & 0 & 0 & 0 & 0 \\
\hline Round block & 18 & 0 & 1 & 0 & 0 \\
\hline Batwing mastopexy & 6 & 0 & 1 & 0 & 0 \\
\hline Inferior pedicle mammoplasty & 6 & 1 & 0 & 2 & 1 \\
\hline LD flap & 6 & 0 & 0 & 0 & 1 \\
\hline Lower inner: V- mammoplasty & 6 & 0 & 0 & 0 & 0 \\
\hline Fish hook rotational flap & 3 & 2 & 0 & 0 & 0 \\
\hline Sup. pedicle mammoplasty & 6 & 0 & 1 & 0 & 2 \\
\hline Total & 60 & 3 & 3 & 2 & 4 \\
\hline
\end{tabular}

Oncologic outcomes: In the current study, the resected safety margin ranged between 2 and 4.2 $\mathrm{cm}$ (mean $3.4 \mathrm{~cm}+0.79$ ), the local re $\neg$ currence occurred in 2 patients (3.3\%) in a 24 months followup period

Esthetic evaluation: We utilized two scales for cosmetic evaluation; the first was subjective according to the degree of patient satisfaction compared to the preoperative breast using a fivepoint scale, 27 patients graded their satisfaction as five "excellent" (45\%) most of them underwent either round block or batwing technique, 21 patients graded their satisfaction as four "good"(35\%) most of them underwent either level I, Mini LD flap or superior pedicle mammoplasty technique, 9 patients graded as three "fair" (15\%) most of them underwent $\mathrm{V}$ - mammoplasty, and 3 patients graded as two "poor"(5\%) most of them underwent Fish hook rotational flap. No patient graded as one "bad" (Table 6). The satisfaction score ranged from 2 to 5 with a median score of 4 and mean score of $4.2 \pm 0.87$

Table 6: Patient's satisfaction score

\begin{tabular}{|c|c|c|c|c|c|c|}
\hline \multirow[b]{2}{*}{ Surgical technique } & \multirow[b]{2}{*}{ No. } & \multicolumn{5}{|c|}{ Patient satisfaction score } \\
\hline & & $\begin{array}{c}1 \\
\text { (Bad) }\end{array}$ & $\begin{array}{c}2 \\
\text { (Poor) }\end{array}$ & $\begin{array}{c}3 \\
\text { (Fair) }\end{array}$ & $\begin{array}{c}4 \\
\text { (Good) }\end{array}$ & $\begin{array}{c}5 \\
\text { (Excellent) }\end{array}$ \\
\hline Upper inner: Level 1 oncoplastic & 9 & 0 & 0 & 3 & 6 & 0 \\
\hline Round block & 18 & 0 & 0 & 0 & 0 & 15 \\
\hline Batwing mastopexy & 6 & 0 & 0 & 0 & 0 & 6 \\
\hline Inf. pedicle mammoplasty & 6 & 0 & 0 & 0 & 3 & 3 \\
\hline LD flap & 6 & 0 & 0 & 0 & 6 & 0 \\
\hline Lower inner: V- mammoplasty & 6 & 0 & 0 & 6 & 0 & 0 \\
\hline Fish hook rotational flap & 3 & 0 & 3 & 0 & 0 & 0 \\
\hline Sup. pedicle mammoplasty & 6 & 0 & 0 & 0 & 6 & 3 \\
\hline Total & 60 & 0 & $3(5 \%)$ & $9(15 \%)$ & $21(35 \%)$ & 27 (45\%) \\
\hline
\end{tabular}


The second scale was objective and was done by two surgeons and a trained nurse, rated on a visual analog scale from 1 (unacceptable result) to 10 (excellent result). 6 cases $(10 \%)$ was given the grade 10 "excellent", 9 cases (15\%) were given the grade nine, 18 cases (30\%) were given the grade eight, 15 cases (25\%) were given the grade seven, 9 cases $(15 \%)$ were given the grade six, and 3 cases (5\%) was given the grade five (Table 7). The Surgical team assessment score ranged from 5 to 10 with a median score of 8 and mean score of $8.15 \pm 1.45$.

Table 7: Surgical team assessment

\begin{tabular}{|c|c|c|c|c|c|c|c|}
\hline \multirow[b]{2}{*}{ Surgical technique } & \multirow[b]{2}{*}{ No. } & \multicolumn{6}{|c|}{ Surgical team assessment score } \\
\hline & & $\begin{array}{c}5 \\
\text { (Poor) }\end{array}$ & $\begin{array}{c}6 \\
\text { (Fair) }\end{array}$ & $\begin{array}{c}7 \\
\text { (Good) }\end{array}$ & $\begin{array}{c}8 \\
\text { (V Good) }\end{array}$ & $\begin{array}{c}9 \\
\text { (Excellent) }\end{array}$ & $\begin{array}{c}10 \\
\text { (Outstanding) }\end{array}$ \\
\hline Upper inner: Level 1 oncoplastic & 9 & 0 & 3 & 3 & 3 & 0 & 0 \\
\hline Round block & 18 & 0 & 0 & 2 & 10 & 3 & 3 \\
\hline Batwing mastopexy & 6 & 0 & 0 & 0 & 2 & 1 & 3 \\
\hline Inf. pedicle mammoplasty & 6 & 1 & 0 & 2 & 1 & 2 & 0 \\
\hline LD flap & 6 & 0 & 0 & 3 & 2 & 1 & 0 \\
\hline Lower inner: V- mammoplasty & 6 & 0 & 5 & 1 & 0 & 0 & 0 \\
\hline Fish hook rotational flap & 3 & 2 & 1 & 0 & 0 & 0 & 0 \\
\hline Sup. pedicle mammoplasty & 6 & 0 & 0 & 4 & 0 & 2 & 0 \\
\hline Total & 60 & $3(5 \%)$ & $9(15 \%)$ & $15(25 \%)$ & $18(30 \%)$ & $9(15 \%)$ & $6(10 \%)$ \\
\hline
\end{tabular}

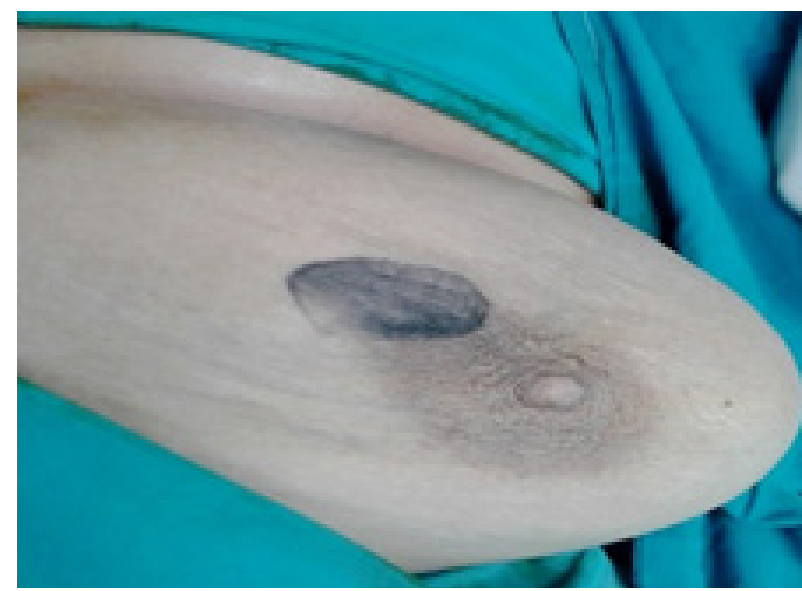

A

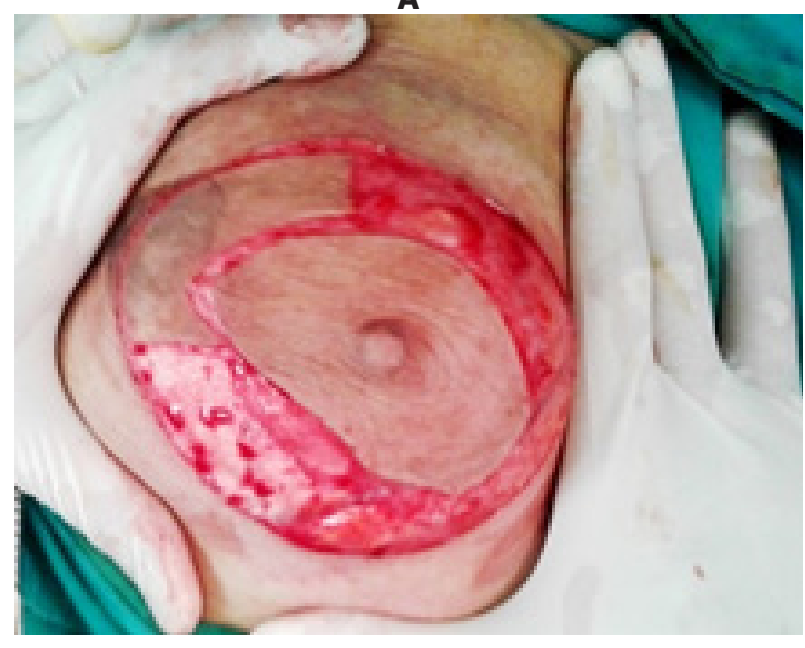

B

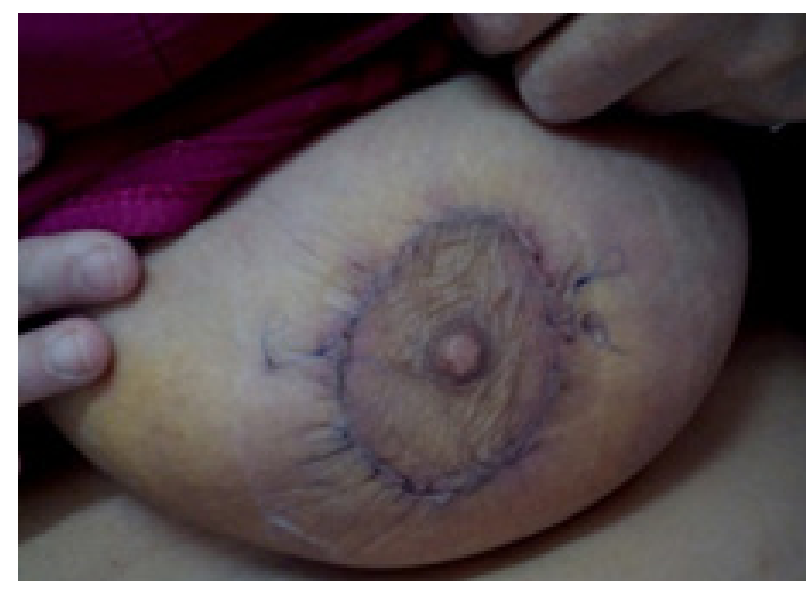

C

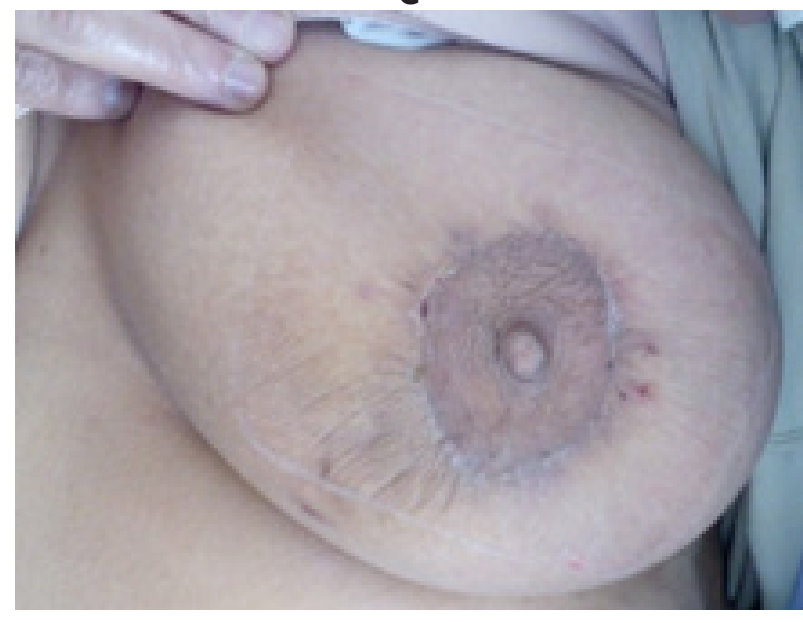

D

Fig 1: Round block technique: 46 years old housewife with $2 \times 1.5 \mathrm{~cm}$ at the left upper inner quadrant. (a) Preoperative with design (b) Intraoperative result (c) Early post-operative result (d) After stitches removal. 


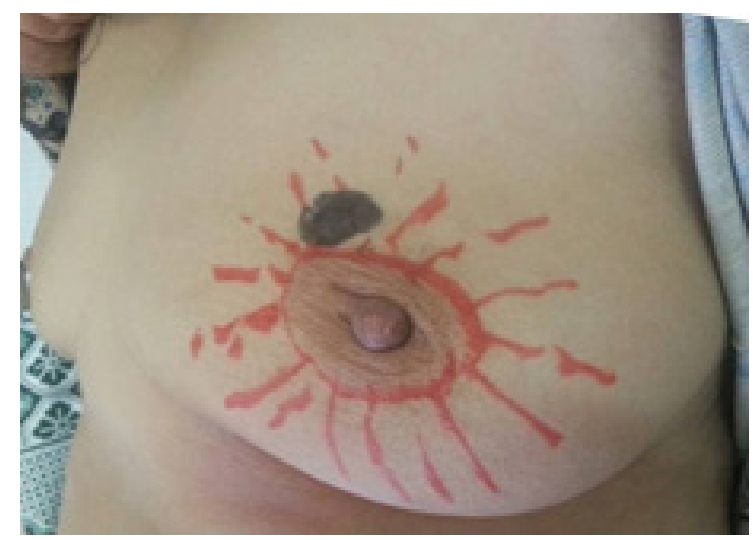

A

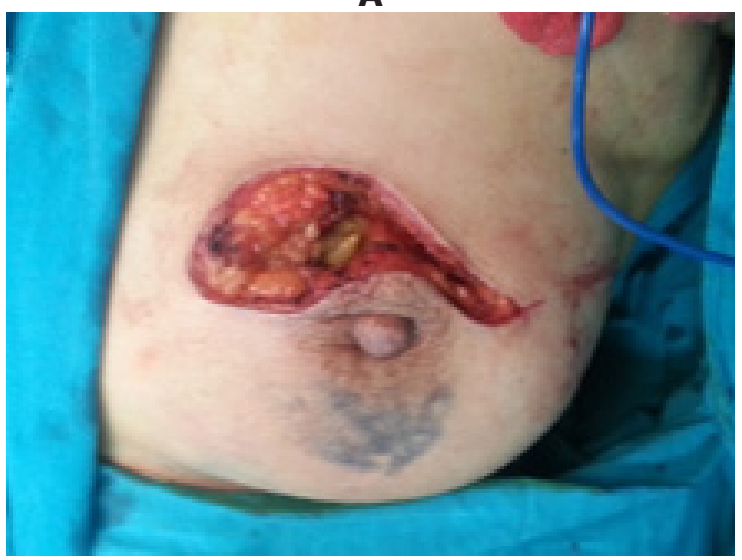

B

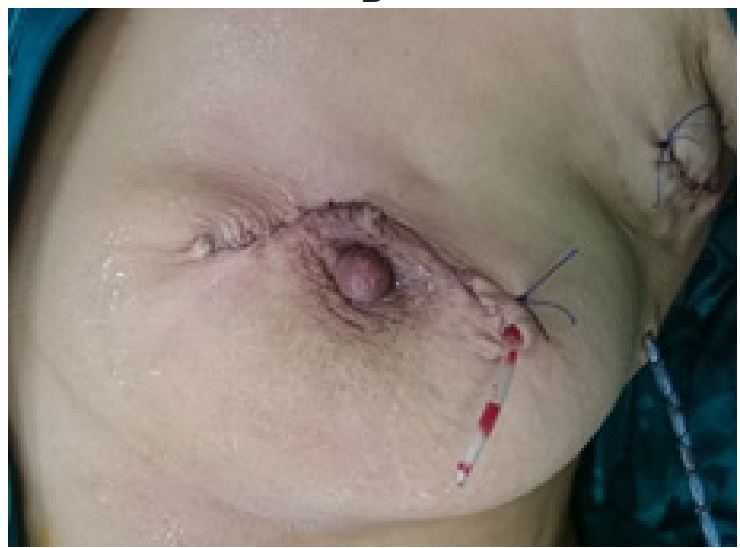

C

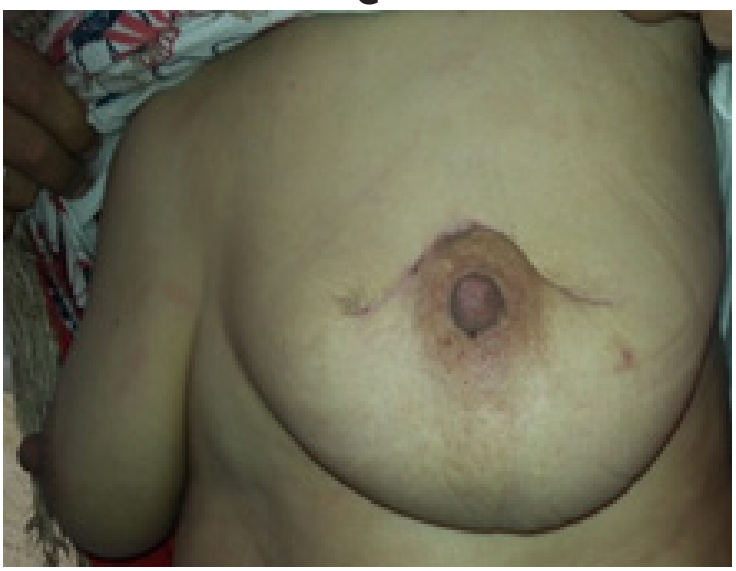

D

Fig 2: Batwing mastopexy: 44 years old housewife with $2 \times 2 \mathrm{~cm}$ tumor at the upper inner quadrant. (a) Preoperative. (b) Intra-operative (c,d) Post-operative result.

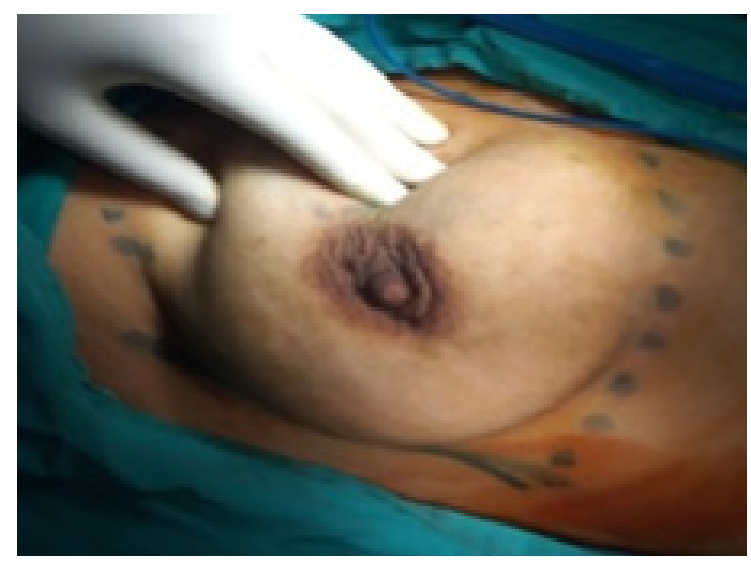

A

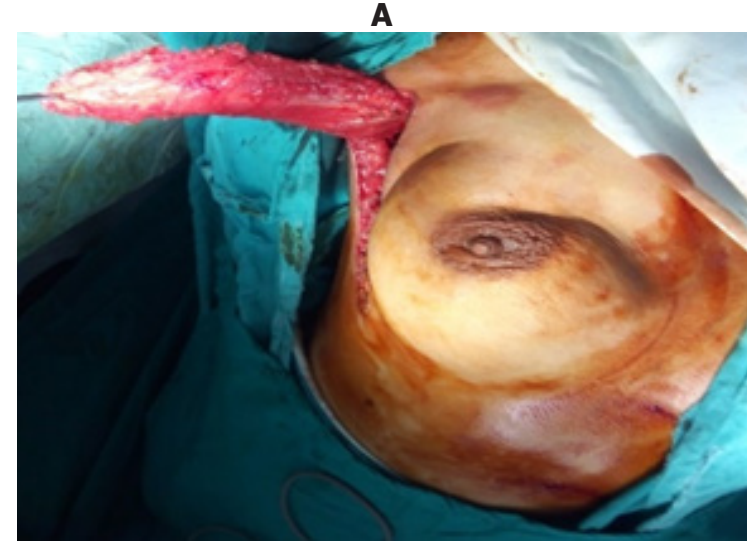

B

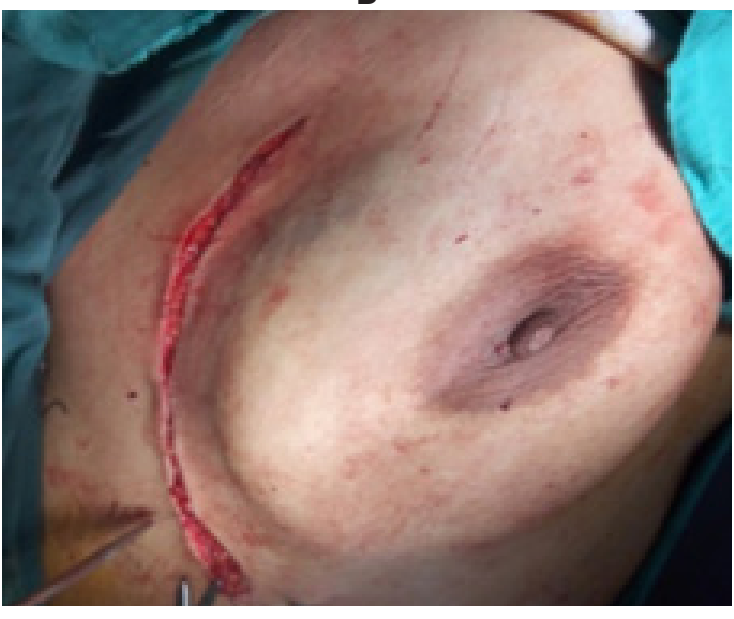

C

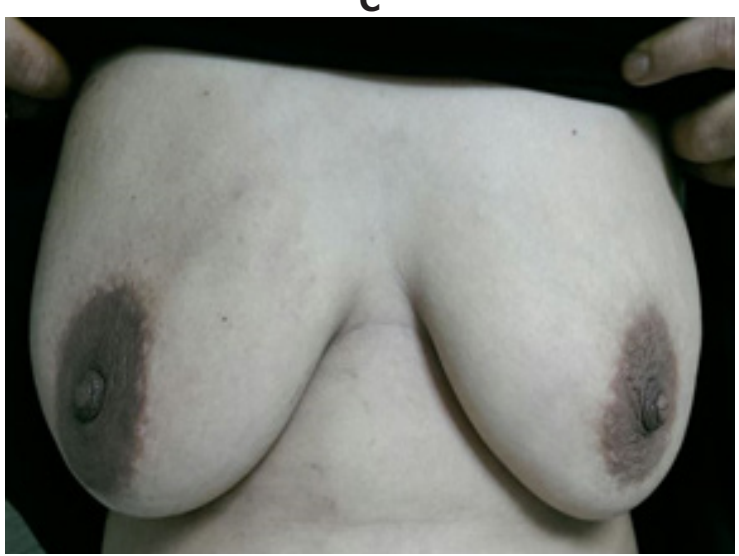

D

Fig 3: Mini LD flap: 36 years old house wife with $3.5 \times 3 \mathrm{~cm}$ tumor at the right upper inner quadrant. $(a, b, c)$ Intra-operative. (d) Post-operative result. 


\section{Discussion}

Breast-conserving surgery is an excellent option for women who choose it, provided that it can be performed without compromising the effectiveness of treatment whilst achieving an acceptable cosmetic result. The measurable outcomes of breast-conserving surgery are survival, local recurrence rates, cosmoses and patient satisfaction. Any assessment of treatment by breast-conserving surgery should report these outcomes for meaningful interpretation of results. ${ }^{3}$ In this study, we adopted oncoplastic techniques for surgical management of inner half breast cancer in patients in whom we expected to have a defect and poor cosmetic outcomes after ordinary BCS. Tumors in this location (inner half) often create a major risk for deformity. The choice of oncoplastic techniques de $\neg$ pended on tumor size and location in relation to breast size and density. Displacement oncoplastic techniques were performed in medium sized breast, while breast re $\neg$ placement oncoplastic techniques were performed when a large excised volume was anticipated in small sized breasts. ${ }^{13}$

In the current study, the age ranged from 28 to 61

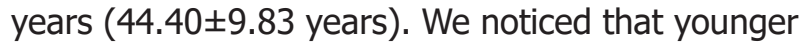
patients had more unfavorable tumor characteristics and higher stages of the disease. Many authors considered young age as a relative contraindication to CBT. ${ }^{14,15}$ We did not exclude young age patients in this study but we tried to insure wider resections, boost radiotherapy to prevent the increased risk of local failure after CBT in younger women.

As regards the tumor size, the mean size of the tumor in the current study was $2.47 \pm 0.98 \mathrm{~cm}$. Fitoussi et al. reported an average tumor size of 2.9 $\mathrm{cm}$ (range 0.4 to $10 \mathrm{~cm}$ ) in a series 540 consecutive patients who underwent oncoplastic breast surgery for breast cancer between 1986 and 2008.17 Some have examined the relationship between excision weight and aesthetic outcome, a simpler concept is tumor excision in proportion to breast size. Cochrane et al. showed that approximately 10 percent was an upper resection limit, with less tolerance medially due to the relative paucity of tissue. ${ }^{12}$ Clough suggested that up to 20 percent volume excisions may yield satisfactory results, but some form of local parenchymal rearrangement or excess skin excision is generally required, once $20 \%$ of the breast volume is excised, there is a clear risk of deformity. ${ }^{13}$

According to the degree of patient satisfaction compared to the preoperative breast using a fivepoint scale, 27 patients graded their satisfaction as five "excellent" (45\%) most of them underwent either round block or batwing technique, 21 patients graded their satisfaction as four "good" $(35 \%)$ most of them underwent either level I, Mini LD flap or superior pedicle imammoplasty technique, 9 patients graded as three "fair" $(15 \%)$ most of them underwent $\mathrm{V}$ - mammoplasty, and 3 patients graded as two "poor" $(5 \%)$ most of them underwent Fish hook rotational flap. No patient graded as one "bad" (Table 6). The satisfaction score ranged from 2 to 5 with a median score of 4 and mean score of $4.2 \pm 0.87$.

Tomoko Ogawa had a series of 18 patients treated by round block technique, his cosmetic results were found to be excellent in three cases $(16.7 \%)$, good in eight cases $(44.4 \%)$, fair in five cases $(27.8 \%)$, and poor in two cases (11.1\%) so, unacceptable outcomes (either fair or poor) were observed in seven cases (38.9\%). Our excellent result after round block technique may be attributed to that we did not excise more than $20 \%$ of the breast volume in contrast to Ogawa who exceeded $20 \%$ excision volume in some of his cases. ${ }^{16}$

Modifying the skin reduction pattern as described by Donald A. Hudson and F. Santanelli may enable mammoplasty for upper quadrentectomy to replace the skin area removed with tumorectomy from the upper quadrants. ${ }^{17}$ Extended inferior pedicle to replace defects outside the reduction pattern was reported by McCulley and Macmillan from Nottingham Instead of sacrificing breast tissue above the NAC, it is retained on the same pedicle and advanced to fill a superior glandular defect. ${ }^{18}$

In the current study 15 patients had lower inner quadrant tumor; 6 patients were treated by lower inner quadrant $\mathrm{v}$ mammoplasty described by Clough; in our study the cosmetic result in these 6 cases (10\%) was rated as fair in comparison to Clough who had excellent result in $68 \%$ and good results in $26 \%$ and fair results in $5 \%$. In our study there was no complication with the technique or local recurrence in comparison with Clough who had complications in $9.1 \%$ of patients and one case $(2.2 \%)$ of local recurrence. ${ }^{10}$ This difference may be due to our narrow scale which requires more studies concerning this technique. 6 patients with lower inner tumor were treated with superior pedicle reduction mammoplasty that results in inverted $\mathrm{T}$ and periareolar scars as seen in most breast reduction patients. In the current study 3 cases $(5 \%)$ was treated by fish hook incision inferior rotational flap described by Seokwon Lee et al. In our study the cosmetic result was poor because the patient developed complication in the form of skin necrosis in the most distal part of the flap in 2 out of 3 cases, despite it resolved with dressings the patient rated her satisfaction as poor in contrast to Seokwon Lee who had excellent and good results in most of his cases with rate of complication equivalent to $5.8 \%$ in the form of partial wound dehiscence and small fat necrosis. ${ }^{11}$ 
In the current study 6 patients had upper inner quadrant tumor were treated by tissue replacement technique using mini-LD flap through a lateral breast crease incision to raise the LD muscle flap and also to do the quadrentectomy or partial mastectomy with axillary dissection through the same incision as described by Rainsbury. ${ }^{19}$ with patient satisfaction score of 4 (good) in the 6 cases. Bostwick explored the use of LD muscle transfer through the axillary incision used in axillary dissection to fill defects left after wide local excision for breast cancer. ${ }^{20}$

Contralateral symmetrisation procedure was undertaken in 2 cases in lour study upon the patient request, one case had superior pedicle reduction imammoplasty and one case had inferior pedicle reduction mammoplasty. The major advantage of simultaneous breast reduction is that it can avoid further surgery when the cancer is successfully removed with clear margins and can achieve excellent or outstanding cosmetic results. Some surgeons like Riccardo Masetti have incorporated contralateral breast reduction into their practices with acceptable results. ${ }^{21}$ On the other hand some surgeons recommend that the contralateral procedure is postponed until final pathology. If positive margins are encountered during final analysis, re-excision or mastectomy will need to be done, at which point the contralateral reduction could prove inadequate. ${ }^{21}$

In the current study 12 patients (20\%) experienced some minor complications and all were treated conservatively. 3 case had skin necrosis (5\%), one case after inferior pedicle mammoplasty and 2 cases after fish hook rotational flap. All cases had small area of skin necrosis at the most distal part of the flap and ended only by superficial epidermolysis and healed spontaneously with frequent dressings. 3 case (5\%) developed seroma that resolved spontaneously. 4 cases $(6.7 \%)$ had superficial wound infection and treated with antibiotics and frequent dressings. 2 cases (3.3\%) had wound dehiscence that healed spontaneously by dressing and did not require any surgical intervention. Our complication rate is comparable to those reported by other studies. Fitoussi et al, reported that the rate of complication was 16.3 percent in a series of 540 patients $^{2}$ Kronowitz et al. states that the complications rate of $\beta 3$ patients who underwent oncoplastic procedures were $24 \%,{ }^{22}$ while Munhoz et al reported a" complications rate of $17 \%$ in 74 patients operated by oncoplastic breast surgery. ${ }^{23}$

In the current study, the resected safety margin ranged between 2 and $4.2 \mathrm{~cm}$ (mean $3.4 \mathrm{~cm}$ ), the local recurrence occurred in 2 patients $(3.3 \%)$ in 24 months follow-up period. Holland et al. reported that the likelihood of residual disease is small when margin widths exceed $10 \mathrm{~mm} .{ }^{24}$ Losken et al., in a series of 63 patients, reported a $2 \%$ recurrence rate after 40 months follow-up. ${ }^{25}$ Kronowitz, et al. observed a $7 \%$ rate of recurrence in 33 patients who underwent oncoplastic procedures after a 36 months follow-up period. ${ }^{22} \mathrm{~A}$ beneficial aspect achieved by oncoplastic procedures is wider resection volume. This has been correlated in many studies to the local recurrence rate. Pass et al. concluded that the 5 and 10 year local recurrence rate decreased when the specimen volume to tumor volume ratio increased and that this ratio was the only treatment-related variable associated with local recurrence. ${ }^{26}$

\section{Conclusion}

The inner half breast cancer are challenging as the risk of deformity is high if managed by ordinary breast conserving surgery. Oncoplastic techniques are feasible and could be applied in good selected cases of inner half breast cancer with good oncological and cosmetic results. Level 1 oncoplastic technique is the simplest oncoplastic technique provided that the excision volume does not exceed $20 \%$ of the breast volume. In large ptotic breasts reduction mammoplasty techniques are considered good option whether superior or inferior pedicled with good patient satisfaction especially when combined with symmetrization technique. Round block technique was the most frequent technique used in medium sized tumors with the best cosmetic result. Batwing mastopexy is a good choice for tumors in the upper inner quadrant while $\mathrm{V}$ mammoplasty and fish hook rotational flap provide a good cosmetic and oncological outcome in LIQ tumors without the need of contralateral procedure.

\section{References}

1. Veronesi U, Cascinelli N, Mariani L, Greco M, Saccozzi R, Luini $A$, et al: Twenty-year followup of a randomized study comparing breast conserving surgery with radical mastectomy for early breast cancer. $\boldsymbol{N}$ Engl J Med. 2002; 347(16): 1227-1232.

2. Fitoussi $A D$, Berry $M G$, Famà $F$, Falcou $M C$, Curnier A, Couturaud B, et al: Oncoplastic breast surgery for cancer: Analysis of 540 consecutive cases. Plast Reconstr Surg. 2010 Feb;125(2): 454-462.

3. Asgeirsson KS, Rasheed T, McCulley SJ, Macmillan RD: Oncological and cosmetic outcomes of oncoplastic breast conserving surgery. European Journal of Surgical Oncology (EJSO). 2005; 31(8): 817-823.

4. Zucca-Matthes G, Manconi A, da Costa Viera RA, Michelli RA, Matthes Ado C: The evolution of mastectomies in the oncoplastic breast surgery era. Gland Surgery. 2013; 2(2): 102-106. 
5. Mansfield L, Agrawal A, Cutress RI: Oncoplastic breast conserving surgery. Gland Surg. Aug 2013;2 (3): 158-162.

6. Kollias J, Davies G, Bochner MA, Gill PG: Clinical impact of oncoplastic surgery in a specialist breast practice. ANZ J Surg. 2008; 78(4): 269272.

7. Würinger $\mathrm{E}$, Tschabitscher $\mathrm{M}$ : New aspects of the topography of the mammary gland regarding its neurovascularsupply along a regular ligamentous suspension. Eur J Morphol. 2002; 40(3): 181189.

8. Würinger $\mathrm{E}$ : Refinement of the central pedicle breast reduction by application of the ligamentous suspension. Plast Reconstr Surg. 1999; 103(5): 1400-1410.

9. Nogushi M, Earashi M, Kinoshita K,Taniya K, Miyazaki I: A case with breast cancer under the nipple underwent breast conserving treatment. Breast Cancer. 1994; 1(2): 157-160.

10. Clough KB, Oden S, Ihrai T, Massey E, Nos C, Sarfati I: Level 2 oncoplastic surgery for lower inner quadrant breast cancers: The LIQ-V mammoplasty. Annals of Surgical Oncology. 2013; 20(12): 3847-3854.

11. Lee S, Lee J, Jung Y, Bae Y: Oncoplastic surgery for inner quadrant breast cancer: Fish-hook incision rotation flap. ANZ Journal of Surgery. 2015; [Epub ahead of print].

12. Cochrane $R$, Valasiadou $P$, Wilson $A$, et al: Cosmesis and satisfaction after breast-conserving surgery correlates with the percentage of breast volume excised. Br J Surg. 2003; 90: 1505-1509.

13. Clough KB, Kaufman GJ, Nos C, Buccimazza I, Sarfati IM. Improving breast cancer surgery: a classification and quadrant per quadrant Atlas for oncoplastic surgery. Ann Surg Oncol. 2010; 17(5): 1375-1391.

14. Kurtz J M, Spitalier J M: Mammary recurrences in women younger than forty. Int $\boldsymbol{J}$ Radiat Oncol Biol Phys. 1988; 15(2): 271-276.

15. Neuschatz AC, DiPetrillo T: Long-term followup of a prospective policy of margin-directed radiation dose escalation in breast-conserving therapy. Cancer. 2003; 97(1): 30-39.

16. Ogawa T: Usefulness of breast-conserving surgery using the round block technique or modified round block technique in Japanese females. Asian Journal of Surgery. 2014; 37(1): 8-14.
17. Paolini FS, Campanale A, Longo B, Amanti C: Modified wise-pattern reduction mammaplasty, a new tool for upper quadrantectomies: A preliminary report. Ann Surg Oncol. 2009; 16: 1122-1127.

18. Mcculley SJ, Macmillan RD: Therapeutic mammaplasty-Analysis of 50 consecutive cases. British Journal of Plastic Surgery. 2005; 58: 902907.

19. Rainsbury RM: Breast sparing reconstruction with latissimus dorsi miniflaps. Eur J Surg Oncol. 2002; 28(8): 891-895.

20. Bostwick J, Minticciolo D L, Ross D, Eaves F, Styblo T: Autologous breast reconstruction with endoscopic latissimus dorsi with musculosubcutaneous flaps in patients choosing breastconserving therapy: Mammographic appearance. Am J Radiol. 1996; 167: 385-389.

21. Masetti R, Di Leone A, Franceschini G, Magno $S$, Terribile D, Fabbri MC, et al: Oncoplastic techniques in the conservative surgical treatment of breast cancer: an overview. Breast J. 2006; 12(5 Suppl 2): S174-S180.

22. Kronowitz SJ, Feledy JA, Hunt KK, Kuerer HM, Youssef A, Koutz CA, et al: Determining the optimal approach to breast reconstruction after partial mastectomy. Plast Reconstr Surg. 2006; 117: 1-11.

23. Holland $\mathrm{R}$, Hendriks JH, Vebeek AL, Mravunac M, Schuurmans Stekhoven JH: Extent, distribution, and mammographic/histological correlations of breast ductal carcinoma in situ. Lancet. 1990; 335: 519-522.

24. Munhoz AM, Montag E, Arruda EG, et al. Critical analysis of reduction mammaplasty techniques in combination with breast conservation surgery for early breast cancer treatment. Plast Reconstr Surg. 2006; 117: 1091-103.

25. Losken A, Styblo TM, Carlson GW, Jones GE, Amerson BJ: Management algorithm and outcome evaluation of partial mastectomy defects treated us $\neg$ ing reduction or mastopexy techniques. Ann Plast Surg. 2007; 59: 235-342.

26. Pass H, Vicini FA, Kestin LL, Goldstein NS, Decker D, Pettinga J, et al: Changes in management techniques and patterns of disease recurrence over time in patients with breast carcinoma treated with breast-conserving therapy at a single institution. Cancer. 2004; 101: 713-720. 


\title{
Retrospective Evaluation of Thyroidectomy in Patients with Solitary Thyroid Nodule with Preoperative Diagnosis of Follicular Neoplasm by FNAC
}

\author{
Ahmed S. M. Omar, MD; Mohab G. Elbarbary, MD; Wadie Boshra, MD, MRCS \\ Department of General Surgery, Ain Shams University, Egypt
}

Background: FNA diagnosis of follicular neoplasm does not differentiate between benign and malignant tumor. This gray zone is problematic since the malignancy risk is low but not excluded. The aim of this study is to determine the optimal surgical approach for patients with STN diagnosed as follicular neoplasm by FNAC.

Patients and methods: Retrospective analysis of patients with STN with follicular or suspicious for follicular neoplasm who underwent thyroidectomy between November 2013 and June 2017. Medical records were reviewed for patient demographics, nodule size, operative time, and final histopathology.

Results: In the study period, 48 patients with follicular neoplasm were included. Hemithyroidectomy was done in 42 patients $(87.5 \%)$, while total thyroidectomy in 6 patients $(12.5 \%)$. Five patients $(10.41 \%)$ needed completion thyroidectomy. Eleven patients $(22.91 \%)$ had thyroid cancer. Papillary cancer was the most common type (9 patients [18.75\%]), while 2 patients $(4.16 \%)$ had a diagnosis of follicular cancer.

Conclusion: Hemithyroidectomy should be the initial approach for STN with follicular neoplasm. The decision may be modified to total thyroidectomy for suspicious sonographic patterns or intraoperative suspicion of malignancy (hard indurated nodule with surrounding adhesions and gritty cut surface). Male gender, nodule size of $\geq 4 \mathrm{Cm}$, and age are not predictive for thyroid cancer.

Key words: Follicular neoplasm, FNAC, Hemithyroidectomy, Total thyroidectomy.

\section{Introduction}

Thyroid nodules have a clinical prevalence between $5.3 \%$ and $6.4 \%$ for women and between $0.8 \%$ and $1.6 \%$ for men. ${ }^{1}$ The prevalence seen on ultrasonography (US) is 10 times higher between $11 \%$ and $50 \%$. They are commonly benign; however, $5-15 \%$ proved to be malignant. ${ }^{2-6}$

Different imaging techniques are now used for preoperative diagnosis of solitary thyroid nodule (STN) like high resolution US, radio nucleotide scanning, etc. but fine needle aspiration cytology (FNAC) is regarded as the single and most cost-effective procedure. $^{7}$ The suspicious features of a malignant nodule on US can be a solid hypoechoic mass, taller-than-wide shape, irregular shape, speculated margin, blurred or indistinct margin, micro-and macro calcifications, disrupted calcified rim, absent or thick incomplete halo, and intranodular vascular pattern. The features of a benign nodule on US can be isoechogenicity and spongiform appearance, cystic with a colloid clot, complete halo, and giraffelike or diffusely hyperechoic pattern. ${ }^{8}$ The US features of thyroid nodules are discussed by Thyroid Imaging, Reporting and Data System (TI-RADS) proposed by the American College of Radiology, which uses a standardized scoring system to provide recommendations for the management of thyroid nodules (Table 1). ${ }^{9}$

Table 1: ACR TI-RADS ${ }^{9}$

\begin{tabular}{|c|c|c|c|c|c|c|}
\hline Score 0 & \multicolumn{2}{|l|}{ Score 1} & \multicolumn{2}{|c|}{ Score 2} & \multicolumn{2}{|c|}{ Score 3} \\
\hline $\begin{array}{l}\text {-Cystic } \\
\text {-Spongiform } \\
\text {-Anechoic } \\
\text {-Wider than tall } \\
\text {-Smooth margin } \\
\text {-Ill-defined margin } \\
\text {-Large comet-tail }\end{array}$ & \multicolumn{2}{|c|}{$\begin{array}{l}\text {-Mixed (cystic/solid) } \\
\text {-Hyperechoic } \\
\text {-Isoechoic } \\
\text {-Macrocalcifications }\end{array}$} & \multicolumn{2}{|c|}{$\begin{array}{l}\text {-Solid } \\
\text {-Hypoechoic } \\
\text {-Lobulated or irregular } \\
\text { margin } \\
\text {-Peripheral (rim) calcifications }\end{array}$} & \multicolumn{2}{|c|}{$\begin{array}{l}\text {-Very hypoechoic } \\
\text {-Taller than wide } \\
\text {-Extrathyroidal extension } \\
\text {-Punctate echogenic foci }\end{array}$} \\
\hline 0 points & 2 points & \multicolumn{2}{|l|}{3 points } & 4-6 points & & $\geq 7$ points \\
\hline $\begin{array}{l}\text { TR1: } \\
\text {-Benign } \\
\text {-Cancer risk: } 0.3 \%\end{array}$ & $\begin{array}{l}\text { TR2: } \\
\text {-Not suspicious } \\
\text {-Cancer risk: } 1.5 \%\end{array}$ & \multicolumn{2}{|c|}{$\begin{array}{l}\text { TR3: } \\
\text {-Mildly suspicious } \\
\text {-Cancer risk: } 4.8 \%\end{array}$} & \multicolumn{2}{|c|}{$\begin{array}{l}\text { TR4: } \\
\text {-Moderately suspicious } \\
\text {-Cancer risk: } 9.1 \%\end{array}$} & $\begin{array}{l}\text { TR5: } \\
\text {-Highly suspicious } \\
\text {-Cancer risk: } 35 \%\end{array}$ \\
\hline No FNA & No FNA & \multicolumn{2}{|c|}{$\begin{array}{l}\geq 1.5 \mathrm{~cm}: \text { follow up } \\
\geq 2.5 \mathrm{~cm}: \text { FNA }\end{array}$} & $\begin{array}{l}\geq 1 \mathrm{~cm}: \text { follow up } \\
\geq 1.5 \mathrm{~cm}: \text { FNA }\end{array}$ & & $\begin{array}{l}\geq 0.5 \mathrm{~cm}: \text { follow up } \\
\geq 1.0 \mathrm{~cm}: \text { FNA }\end{array}$ \\
\hline
\end{tabular}


FNAC of malignant thyroid nodules reported to have sensitivity and specificity ranges from 65$98 \%$ and $72-100 \%$ respectively. ${ }^{10}$ FNA has emerged as a cornerstone modality in the preoperative management of thyroid lesions because of its reported high accuracy, specificity, cost-utility, and low false negative rate. The widespread utilization of FNA has driven a significant reduction in unnecessary thyroidectomies worldwide as well as a decrease in the use of intraoperative frozen (IOF) sections. In many cases, FNA provides a definitive benign or malignant diagnosis and effectively facilitates the planning of surgical and therapeutic treatment. Among thyroid nodules that undergo FNA, about $19 \%$ are classified as non-diagnostic, $65 \%$ as benign, $5 \%$ as intermediate, $3 \%$ as suspicious for malignancy, and $8 \%$ as malignant. ${ }^{11}$
Reporting of FNAC has improved in the past 10 years with the introduction of classification schemes in order to standardize terminology, to facilitate communication among cytopathologists, endocrinologists and surgeons, and to provide the malignancy risk for specific diagnostic categories. The Bethesda System, a 6-diagnostic-category system, is at present the most used reporting system for thyroid FNAC. ${ }^{12}$ Other classification systems for thyroid FNA are the Royal College of Pathologist classification, ${ }^{13}$ the Italian consensus by the Italian Society for Anatomic Pathology and Cytology jointly with the Italian Division of the International Academy of Pathology (SIAPEC-IAP), ${ }^{14}$ and the Japan Thyroid Association classification. ${ }^{15}$ Table 2 shows the comparison of the diagnostic categories of these classification systems.

Table 2: Comparison of the diagnostic categories of the classification systems

\begin{tabular}{|c|c|c|c|}
\hline Bethesda System (USA) ${ }^{12}$ & $\begin{array}{l}\text { Royal College of } \\
\text { Pathologist (UK) })^{13}\end{array}$ & SIAPEC-IAP (Italy) ${ }^{14}$ & $\begin{array}{l}\text { Japan Thyroid } \\
\text { Association }^{15}\end{array}$ \\
\hline $\begin{array}{l}\text { I: Non-diagnostic: cystic fluid } \\
\text { only }\end{array}$ & $\begin{array}{l}\text { Thy1: Non-diagnostic for } \\
\text { cytological diagnosis } \\
\text { Thy1c: Non-diagnostic for } \\
\text { cytological diagnosis: } \\
\text { cystic lesion }\end{array}$ & $\begin{array}{l}\text { TIR1: Non-diagnostic } \\
\text { TIR1C: Non-diagnostic-cystic }\end{array}$ & 1: Inadequate \\
\hline II: Benign & $\begin{array}{c}\text { Thy2: Non-neoplastic } \\
\text { Thy2c: Non-neoplastic cystic } \\
\text { lesion }\end{array}$ & TIR2: Non-malignant & 2: Normal or benign \\
\hline $\begin{array}{c}\text { III: Atypia of undetermined } \\
\text { significance } \\
\text { or follicular lesion of } \\
\text { undetermined } \\
\text { significance (AUS/FLUS) }\end{array}$ & $\begin{array}{l}\text { Thy3a: Neoplasm possible } \\
\text { atypia/non-diagnostic } \\
\text { Thy3b: Neoplasm possibly } \\
\text { suggesting follicular } \\
\text { neoplasm }\end{array}$ & $\begin{array}{l}\text { TIR3A: Low-risk } \\
\text { indeterminate } \\
\text { lesion }\end{array}$ & $\begin{array}{l}\text { 3: Indeterminate } \\
\text { A. Follicular neoplasms } \\
\text { A1. Favor benign } \\
\text { A2. Borderline } \\
\text { A3. Favor malignant } \\
\text { B. Others (nonfollicular } \\
\text { pattern lesions) }\end{array}$ \\
\hline $\begin{array}{l}\text { IV: Follicular neoplasm or } \\
\text { suspicious for } \\
\text { follicular neoplasm (FN/SFN) }\end{array}$ & & $\begin{array}{l}\text { TIR3B: High-risk } \\
\text { indeterminate } \\
\text { lesion }\end{array}$ & \\
\hline V: Suspicious of malignancy & $\begin{array}{l}\text { Thy4: Suspicious of } \\
\text { malignancy }\end{array}$ & $\begin{array}{l}\text { TIR4: Suspicious of } \\
\text { malignancy }\end{array}$ & 4: Malignancy suspected \\
\hline VI: Malignant & Thy5: Malignant & TIR5: Malignant & 5: Malignancy \\
\hline
\end{tabular}

Table 2 Comparison of the diagnostic categories of the classification systems.

Despite being an important and an effective diagnostic tool, it is difficult to distinguish between follicular adenoma and follicular carcinoma based solely on an FNAC because histologic evidence of capsular and/or vascular invasion is required to determine malignancy for a follicular lesion.16 Approximately $30 \%$ of these FNA biopsies showing follicular lesions prove to be malignant on histologic examination. ${ }^{17}$

Surgical management of follicular neoplasm (FN) following FNAC is still debated. ${ }^{18-22}$ Patients may be either over-treated by total thyroidectomy (TT) for benign lesions or undertreated by hemithyroidectomy (HT) for malignant lesions, this latter setting requiring a completion thyroidectomy (CT). Most resected lesions have benign histology, whereas a minority display well differentiated thyroid carcinoma. In the more recent years, the 
number of FN diagnoses has increased, leading to more thyroid surgical procedures; as a matter of the fact, the malignancy rate associated with FN is generally low (10-30\%). ${ }^{18}$ The aim of this study is to review patients with follicular thyroid lesion whether under treated with hemithyroidectomy or over treated with total thyroidectomy, and to determine the optimal surgical approach for these patients.

\section{Patients and methods}

This retrospective study was carried out in Ain Shams University hospitals in Egypt and in Saudi hospital in Hajja, Yemen. This assessment was approved by the Ethical Committee of the Faculty of Medicine, Ain Shams University, and Saudi hospital in Hajja, Yemen.

The study included 48 patients in the period between November 2013 and June 2017.

\section{Inclusion criteria}

Patients with STN $>1 \mathrm{~cm}$ with FNAC of follicular lesion or suspicious for follicular lesion without any contraindication for general anesthesia.

\section{Exclusion criteria}

Patients with thyroid nodule $<1 \mathrm{~cm}$, enlarged neck lymph nodes, history of neck irradiation, family history of thyroid cancer, metastatic follicular cancer, previous thyroid surgery, patients having any contraindication for general anesthesia, and cases without surgical follow-up.

History, physical examination, laboratory investigations (CBC, liver, kidney functions, free T3, free T4, TSH), neck US, and FNAC, were performed for all patients. All patients underwent thyroid US performed by a radiologist with experience in thyroid sonography. US findings were assessed for nodular status (solitary or multinodular), nodule size, presence of microcalcifications, structure (cystic, solid, or mixed), and echogenicity (isoechoic, hypoechoic, hyperechoic, or mixed). FNA was performed under US guidance by a radiologist using a 25 -gauge needle attached to a $10-\mathrm{ml}$ syringe. Samples were stained with hematoxylin and eosin and evaluated by the pathologist.

Routine pre-operative vocal fold evaluation was performed for all cases. An intraoperative nerve monitoring was not used as it is not available in our hospitals. IOF section examination was not used to determine the extent of thyroidectomy, as adequate histopathologic diagnosis of thyroid disease is based on extensive subsampling of the specimen which is not possible during the frozen section procedure. Hemithyroidectomy was considered the standard intervention for the majority of cases, while total thyroidectomy was reserved for patients with suspicious sonographic patterns or intraoperative suspicion of malignancy (hard indurated nodule with surrounding adhesions and gritty cut surface). Drain was left in all cases.

Recurrent laryngeal nerves were routinely identified and exposed until their insertion into the larynx. Vocal fold paresis was considered definitive (paralysis) 6 months after surgery. Every attempt to preserve the parathyroid glands and their vascularization was made. In cases of suspected devascularized or incidentally removed parathyroid glands, they were sliced, and direct muscular autoimplantation in the sternomastoid muscle was performed. Serum calcium was checked when symptoms or signs of hypocalcemia. Postoperative hypoparathyroidism was considered definitive 6 months after surgery. After hemithyroidectomy, levothyroxine was administered in the majority of cases (mean dose $50 \mathrm{ug}$ ), while total thyroidectomy patients received $100 \mathrm{ug}$ levothyroxine with modification of the dose during follow up. Patients with thyroid cancer were referred to oncology department to receive radioactive iodine.

Clinical data, including age, gender, nodule size, preoperative thyroid function, FNAC, extent of surgery, operation time, post-operative RLN palsy, postoperative hypoparathyroidism, hospital stay, postoperative hypothyroidism and final histopathology, were recorded. Patients were followed up for 18-60 months post-operative, for early and late complications including recurrence. The follow up consisted of US and thyroid function tests every 6 months, and thyroglobulin level in cancer patients.

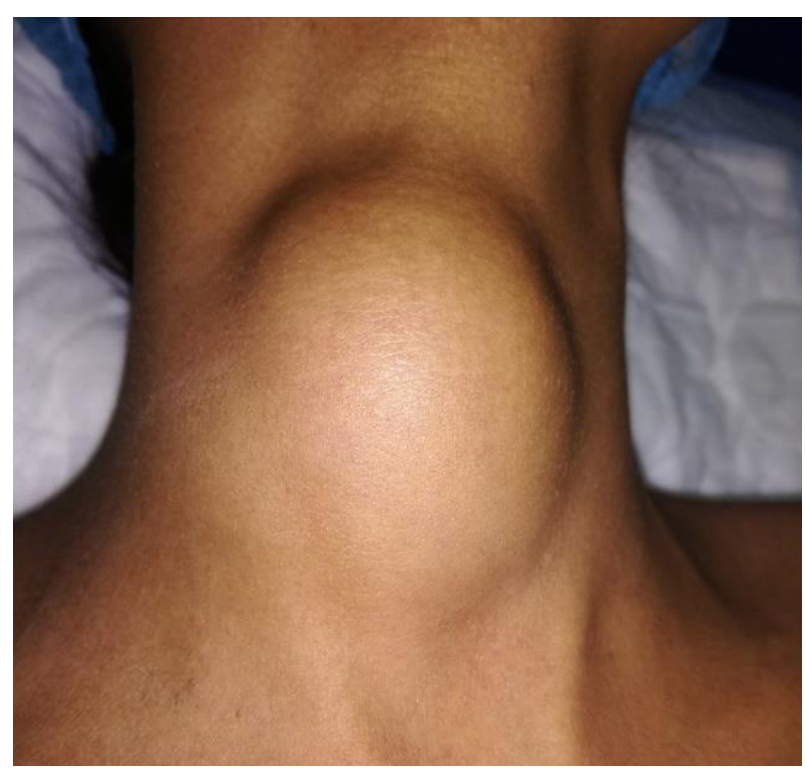

Fig 1: STN (Pre-operative). 


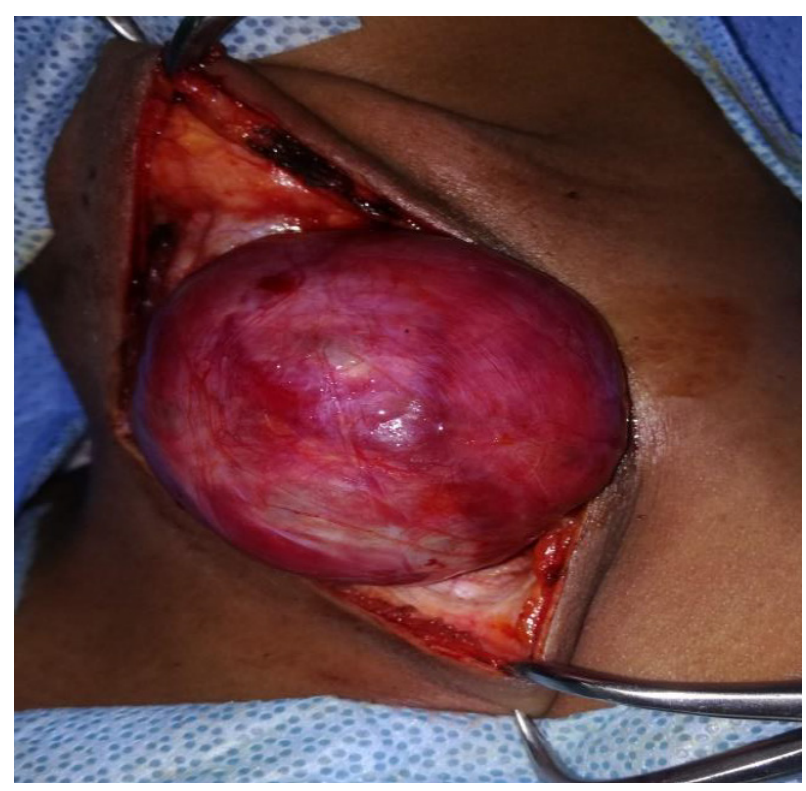

Fig 2: Intra-operative dissection.

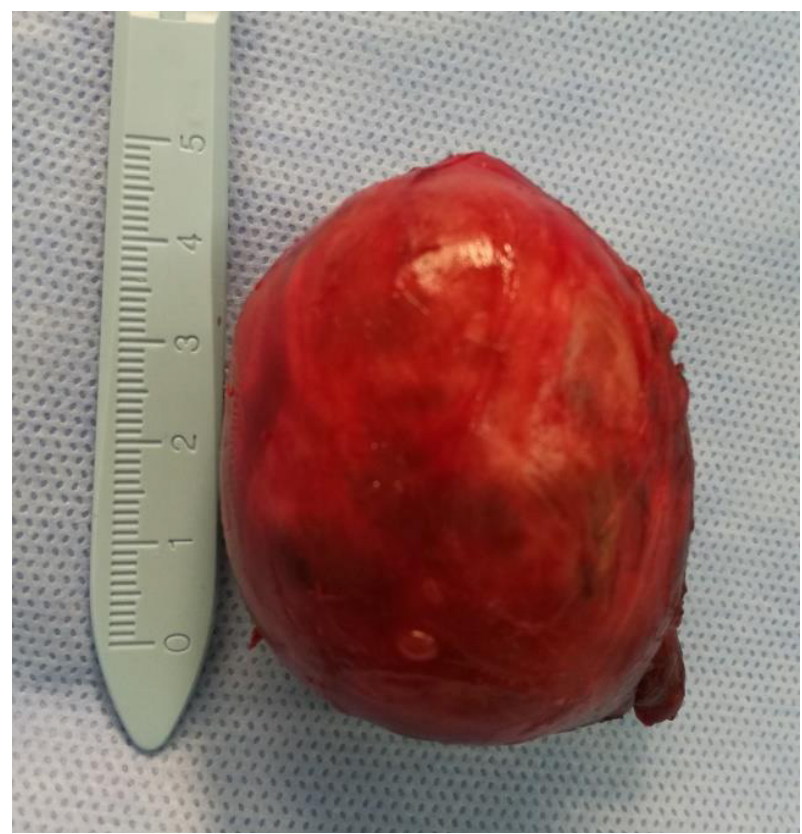

Fig 3: Hemithyroidectomy specimen.

\section{Statistical analysis}

Data were collected and analyzed using computer program IBM SPSS (version 21). Continuous data were presented as mean \pm standard deviation (SD). Categorical data were presented as percentages. Analysis of variance (ANOVA) and the rank-sum test were used to analyze continuous data. The results were regarded significant $(S)$ with $P<0.05$ \& highly significant (HS) with $P<0.01$. $P \geq 0.05$ was regarded non-significant (NS). $\chi 2$ test (with Yates correction and Fisher's exact test) and the Student t or Mann Whitney $U$ tests were used according to the characteristics of the study variables and the conditions of applicability.

\section{Results}

During the study period, 48 patients with STN > $1 \mathrm{Cm}$ with FNAC of FN or suspicious for FN were included. HT was done in 42 patients $(87.5 \%)$, while $\pi$ was done in 6 patients (12.5\%). Eleven patients $(22.91 \%)$ had malignant final histopathology. Five patients $(10.41 \%)$ needed completion thyroidectomy. All patients who underwent total thyroidectomy proved to have thyroid cancer.

Patient age and risk of malignancy (Table 3) The study included 48 patients, 40 females $(83.33 \%)$ and 8 males (16.67\%). The age ranged (19-62 years) with a mean age of $33.02 \pm 11.71$ years. Among 39 patients aged less than 45 years, 10 patients $(25.641 \%)$ had thyroid cancer, while 29 patients $(74.359 \%)$ had benign pathology. In 9 patients aged 45 years or more, only 1 patient $(11.11 \%)$ proved to have thyroid cancer, while 8 patients $(88.89 \%)$ had benign pathology. The $\mathrm{P}$-value was statistically nonsignificant $(0.143$ by t-test).

\section{Patient sex and risk of malignancy (Table 3)} Among 40 females included in the study, 31 female $(77.5 \%)$ had benign pathology and 9 patients (22.5\%) proved to have thyroid cancer. In 8 males, 2 patients $(25 \%)$ had thyroid cancer. The P-value was statistically nonsignificant ( 0.445 by t-test).

\section{Nodule size and risk of malignancy (Table 3)}

The nodule size ranged $(1.3-6.5 \mathrm{Cm})$ with a mean size of $2.925 \pm 1.097 \mathrm{Cm}$.

Among 38 patients with nodule size less than 4 $\mathrm{Cm}, 11$ patients $(28.95 \%)$ had thyroid cancer and 27 patients $(71.05 \%)$ had benign pathology. Ten patients with nodule size of $4 \mathrm{~cm}$ or more, all of them had benign final pathology. The P-value was statistically highly significant for nodule size $<4 \mathrm{Cm}$ ( 0.0002 by $\mathrm{t}$-test). 
Table 3: Patient age, Sex, Nodule size, and risk of malignancy

\begin{tabular}{|c|c|c|c|c|}
\hline Patient age & Number & Benign & Malignant & P value \\
\hline$<45 y$ & $39(81.25 \%)$ & $29(74.359 \%)$ & $10(25.641 \%)$ & \multirow{2}{*}{0.143} \\
\hline$\geq 45$ y & $9(18.75 \%)$ & $8(88.89 \%)$ & $1(11.11 \%)$ & \\
\hline \multicolumn{5}{|l|}{ Sex } \\
\hline Male & $8(16.67 \%)$ & $6(75 \%)$ & $2(25 \%)$ & \multirow[t]{2}{*}{0.445} \\
\hline Female & $40(83.33 \%)$ & $31(77.5 \%)$ & $9(22.5 \%)$ & \\
\hline \multicolumn{5}{|l|}{ Nodule size } \\
\hline $4 \mathrm{~cm}<$ size $\geq 1.3 \mathrm{~cm}$ & $38(79.17 \%)$ & 27 (71.05\%) & $11(28.95 \%)$ & \multirow[t]{2}{*}{0.0002} \\
\hline $6.5 \mathrm{~cm} \geq$ size $\geq 4 \mathrm{Cm}$ & $10(20.83 \%)$ & $10(100 \%)$ & 0 & \\
\hline
\end{tabular}

\section{Operative time (Table 4)}

HT patients had a significantly less operative time than $T$ patients (The P-value was 0.007 by t-test): mean operative time for HT was $57.26 \pm 20.69$ minutes (range 35 to 130 minutes) while for $\pi$, it was $85.83 \pm 17.15$ minutes (range 70 to 110 minutes). Patients with completion thyroidectomy had operative time range 55 to 100 minutes with mean time of $72 \pm 18.23$ minutes.

\section{Postoperative hospital stay (Table 4)}

Mean postoperative hospital stay was $1.33 \pm 0.47$ days (range 1 to 2 days) in the HT patients and $3.33 \pm 2.16$ days (range 2 to 7 days) in the $T$ patients (The P-value was 0.073). In patients with completion thyroidectomy, the mean hospital stay was $3.4 \pm 1.94$ days (range 2 to 6 days).

\section{Postoperative complications (Table 4)}

In most cases no complications were reported; noteworthy, surgical morbidities were significantly lower (The P-value was 0.002) in HT than TT and completion thyroidectomy. Postoperative complications were transient hypocalcemia in 4 (8.33\%) patients (2 CT and 2 TT). Two (4.16\%) patients after total thyroidectomy had temporary laryngeal nerve palsies (complete recovery after 3 months). Neither permanent recurrent laryngeal nerve palsy nor permanent hypoparathyroidism occurred after either procedure. The laryngeal nerve was identified in all cases. No recurrence was found during the follow up period.

Table 4: Operative time, hospital stay, and complications

\begin{tabular}{lccc}
\hline & Hemithyroidectomy & Total thyroidectomy & Completion thyroidectomy \\
\hline Mean operative time & $57.26 \pm 20.69 \mathrm{~min}$ & $85.83 \pm 17.15 \mathrm{~min}$ & $72 \pm 18.23 \mathrm{~min}$ \\
Range & $35-130 \mathrm{~min}$ & $70-110 \mathrm{~min}$ & $55-100 \mathrm{~min}$ \\
Mean hospital stay & $1.33 \pm 0.47$ days & $3.33 \pm 2.16$ days & $3.4 \pm 1.94$ days \\
Range & $1-2$ days & $2-7$ days & $2-6$ days \\
Transient hypocalcemia & - & $2(4.16 \%)$ & $2(4.16 \%)$ \\
Temporary RLN paresis & - & $2(4.16 \%)$ & - \\
\hline
\end{tabular}

\section{Final histopathology (Table 5)}

Thyroid cancer was diagnosed in 11 patients (22.91\%). Papillary cancer was the most common type (9 patients [18.75\%]), while 2 patients $(4.16 \%)$ had a diagnosis of follicular cancer. Of the 9 patients with papillary cancer, 2 patients had a follicular variant of papillary cancer. The benign histologic diagnoses were follicular adenoma in 16 cases $(33.33 \%)$, Hashimoto thyroiditis in 2 cases $(4.16 \%)$, and simple nodular goiter in 19 patients (39.6\%).

Table 5: Final histopathology

\begin{tabular}{ll}
\hline Benign Pathology & Thyroid cancer \\
\hline Follicular adenoma: 16 patients $(33.33 \%)$ & Papillary cancer:9 patients $18.75 \%$ \\
Hashimoto thyroiditis: 2 patients $(4.16 \%)$ & Follicular cancer: 2 patients $4.16 \%$ \\
Simple nodular goiter: 19 patients $(39.6 \%)$. & \\
\hline
\end{tabular}


Considering the total follicular neoplasms in this study, hemithyroidectomy was considered adequate treatment for 37 patients (77.08\%), while in 5 patients with cancer who underwent HT (10.41\%), it had been necessary a completion thyroidectomy. The mean time between HT and completion thyroidectomy was $34.1 \pm 15.1$ days. The histological examination never revealed malignancy in the specimen removed during completion thyroidectomy. Furthermore we observed that TT guided by clinical, suspicious sonographic patterns or intraoperative suspicion of malignancy was an optimal treatment in all cases, as all of them proved to have malignant pathology. In patients who required completion thyroidectomy, the pathology was micro carcinoma which is hardly to suspect malignancy intra-operatively.

\section{Discussion}

The most relevant challenge for surgeons managing a patient with a thyroid nodule is to define whether it is malignant or benign. This classification is routinely performed with a FNAC, which has a high sensitivity and specificity. ${ }^{23}$ However, in at least $15-20 \%$ of cases, ${ }^{24}$ the cytological results do not offer enough information to determine the type of nodule, resulting in what is currently called an undetermined, follicular lesion or $\mathrm{FN}$, under the recent Bethesda classification. ${ }^{25}$

Indeterminate FNA results which were subclassified into follicular, microfollicular, and Hürthle cell neoplasms, are due to poorly defined morphologic criteria to distinguish benign from malignant lesions. In particular, the diagnosis of follicular carcinoma usually requires an assessment of vascular or capsular (thyroid capsule or tumor capsule or both) invasion, findings that necessitate histological evaluation; therefore, surgical excision of all indeterminate thyroid nodules is recommended. ${ }^{26}$

Frozen section has its limitations in detecting malignancy in thyroid surgery. Firstly, the diagnosis of malignancy depends on finding capsular and/ or vascular invasion which is difficult due to the limited number of slices available during the frozen section, ${ }^{27}$ also, micro-carcinomas with a diameter of less than $1 \mathrm{~cm}$ are also difficult to find. Secondly, is the problem of sampling error. ${ }^{27}$ In a study in small hospitals in the USA, frozen sections in thyroid and/ or parathyroid tissue were the third most frequent cause of discordant diagnosis with the permanent section, mainly because of sampling error. Thirdly, the interpretation of frozen sections is made more difficult by freezing artifacts that cause cellular distortion, blood vessel distortion and collapse. For instance, it is more difficult to see the ground glass appearance of the nuclei in follicular variants of papillary cancer. ${ }^{28}$
Although patient age has been consistently used as a prognostic indicator for thyroid cancer risk stratification systems, the association between age and preoperative diagnosis of malignancy in individuals with indeterminate cytology has remained unclear. In this study, cancer risk was not increased in patients older than 45 years and it was higher in young ages, but without statistical significance. This matches the study carried out by Antunes and Taveira-Gomes who concluded that younger age, was associated to malignancy. ${ }^{29}$ Schlinkert and colleagues reported that younger patient age predicted malignancy in a cohort of 19 patients with follicular thyroid cancers (FTCs) among 219 patients with a diagnosis of FN who underwent thyroid surgery at the Mayo Clinic. ${ }^{30}$ Furthermore, in a study of 215 patients with FN in a Korean center, cancer was identified in 102 individuals and patient age younger than 20 years or older than 60 years was significantly associated with a final pathologic diagnosis of cancer. ${ }^{31}$

The male sex has been reported to represent a risk factor for malignancy, ${ }^{32,33}$ but this finding has not been confirmed by others, ${ }^{6,34,35}$ nor in the present study. However, in the study performed by Sorrenti and colleagues, males had an increased risk of malignancy when the cytological diagnosis was Hürthle cell neoplasm. ${ }^{36}$

Many studies had reported that bigger nodule sizes were associated with malignancy, ${ }^{35,37}$ but others did not confirm this. ${ }^{6,31,33}$ In the study carried out by Gulcelik et al, they concluded that the mean nodule size was slightly larger in malignant nodules than in benign nodules, but the difference did not reach statistical significance. ${ }^{35}$ Here, overall nodule size did not result as a predictor of malignancy and cancer was significantly higher in nodules smaller than $4 \mathrm{Cm}$. It is conceivable that nodules $\geq 4 \mathrm{~cm}$ are generally followed for a longer time before the patient is sent to surgery, and thus, they are benign on histology. On the other hand, aggressive undifferentiated neoplasms grow faster than benign lesions and their wider size can predict malignancy. Many studies had suggested total thyroidectomy for single nodule showing follicular neoplasm in FNAC. Antunes and Taveira-Gomes concluded that hemithyroidectomy was inappropriate in $40.1 \%$ patients with malignancy who required completion thyroidectomy and $23.12 \%$ had no functional benefit because post- hemithyroidectomy hypothyroidism. ${ }^{29}$ Nodular relapse was reported in at least $20.35 \%$ of patients who underwent HT, and they proposed TT for patients with FN preoperative TSH higher than $2.16 \mathrm{mU} / \mathrm{L}$ and, in Bethesda category IV, less than 39.5 yrs. Calò et al, also recommended total thyroidectomy and reported that the rate of malignancy in cytologically indeterminate lesions was high in their study sample compared to other 
reported rates, and in a significant number of cases Hashimoto's thyroiditis was also detected. ${ }^{38}$

Considering the total follicular neoplasms in this study, HT with low morbidity, was considered adequate treatment for 37 patients $(77.08 \%)$, while in 5 patients with cancer who underwent HT $(10.41 \%)$, it had been necessary to do a completion thyroidectomy. This result agreed with Rosato et al. who followed 14,934 patients during 5 years and concluded that HT is the safest thyroidal surgery with a lower morbidity when compared with $\pi .{ }^{39}$

Our data supports previous studies suggesting that in the absence of specific risk factors, such as familiarity, enlarged lymph nodes, neck irradiation, and of contralateral nodules, hemithyroidectomy represents the safest standard of care, reflecting its very low morbidity rate, the shorter hospitalization, the lower costs, the low rate of contralateral unexpected PTC, and the low long term need of completion thyroidectomy. ${ }^{40-42}$ In our experience, a completion thyroidectomy was required in 5 patients $(10.41 \%)$, following definitive diagnosis. Moreover, as a conservative approach, recommendations from American Thyroid Association (ATA) consider that lobectomy alone may be a sufficient treatment for incidental, small $(<1 \mathrm{~cm})$, low-risk, unifocal, intrathyroidal papillary carcinomas, usually carried out for other thyroid pathology, in the absence of sonographically or clinically involved cervical nodal metastases. ${ }^{43}$

\section{Conclusion}

Hemithyroidectomy should be the initial approach for solitary thyroid nodule with follicular neoplasm. The decision may be modified to total thyroidectomy for suspicious sonographic patterns or intraoperative suspicion of malignancy (hard indurated nodule with surrounding adhesions and gritty cut surface). Male gender, nodule size, and age, are not predictive for thyroid cancer.

\section{Conflicts of interest}

There are no conflicts of interest.

\section{References}

1. Wemeau JM, Sadoul JL, d'Herbomez $M$, et al: Guidelines of the French Society of Endocrinology for the Management of Thyroid Nodules. Annales d'Endocrinologie. 2011; 72: 251-281.

2. Alexander EK, Kennedy GC, Baloch ZW, Cibas ES, Chudova D, Diggans J, et al: Preoperative diagnosis of benign thyroid nodules with indeterminate cytology. N Engl $\mathbf{J}$ Med. 2012; 367: 705-715.

3. Lakhani R, Rourke $T$, Jefferis A, Perry L, Ghiacy
S, Wood S: Thy3 cytology: What to do next?. Ann R Coll Surg Engl. 2011; 93: 225-228.

4. Baldini E, Sorrenti S, Catania A, Guaitoli E, Prinzi N, Mocini $R$, et al: Diagnostic utility of thyroglobulin measurement in the fine needle aspirates from cervical lymph nodes: A case report. G Chir. 2012; 33: 387-391.

5. Gheri RG, Romoli E, Vezzosi V, Ragghianti B, Bianchi S, Pedercini S, et al: Follicular nodules (THY3) of the thyroid: we recommend surgery. J Endocrinol Invest. 2011; 34: 83-87.

6. Ratour J, Polivka M, Dahan H, Hamzi L, Kania R, Dumuis $M L$, et al: Diagnosis of follicular lesions of undetermined significance in fine-needle aspirations of thyroid nodules. $\boldsymbol{J}$ Thyroid $\boldsymbol{R e s}$. 2013, 2013: 250347.

7. Guhamallik $M$, Sengupa $S$, Bhattacharya NK, Basa N, Roy S, Ghosh AK, et al: Cytodiagrosis of thyroid lesions-usefulness and pitfalls: A study of 288 cases. J Cytol. 2008; 25: 6-9.

8. Moon WJ, Jung SL, Lee JH, Na DG, Baek JH, Lee $\mathrm{YH}$, et al: Benign and malignant thyroid nodules: US differentiation multicenter retrospective study. Radiology. 2008; 247: 762-770.

9. Tessler FN, Middleton WD, Grant EG, et al: ACR thyroid imaging, reporting and data system (TI-RADS): White paper of the ACR TI-RADS Committee. J Am Coll Radiol. 2017; 14: 587595.

10. Shahid F, Mirza T, Mustafa $S$, Sabahat $S$, Sharafat S: An experiential status of fine needle aspiration cytology of head and neck lesions in a tertiary care scenario. $\boldsymbol{J}$ Bas $\boldsymbol{A p p l} \boldsymbol{S \boldsymbol { c i }}$. 2010; 6: 159-162.

11. Yang J, Schnadig V, Logrono R, et al: Fine-needle aspiration of thyroid nodules: A study of 4703 patients with histologic and clinical correlations. Cancer. 2007; 111: 306-315.

12. Cibas ES, Ali SZ: The Bethesda system for reporting thyroid cytopathology. Thyroid. 2009; 19(11): 1159-1165.

13. Lobo C, McQueen A, Beale T, Kocjan G: The UK Royal College of Pathologists thyroid fine-needle aspiration diagnostic classification is a robust tool for the clinical management of abnormal thyroid nodules. Acta Cytol. 2011; 55: 499-506.

14. Nardi F, Basolo F, Crescenzi A, Fadda G, Frasoldati $A$, Orlandi $F$, et al: Italian consensus for the classification and reporting of thyroid cytology. 
15. Kakudo K, Kameyama K, Miyauchi A, Nakamura $\mathrm{H}$ : Introducing the reporting system for thyroid fine-needle aspiration cytology according to the new guidelines of the Japan thyroid association. Endocr J. 2014; 61(6): 539-552.

16. Davidov T, Trooskin SZ, Shanker BA, et al: Routine second opinion cytopathology review of thyroid fine needle aspiration biopsies reduces diagnostic thyroidectomy. Surgery. 2010; 148(6): 1294-1299.

17. Baloch ZW, Fleisher S, LiVolsi VA, Gupta PK: Diagnosis of "follicular neoplasm": A gray zone in thyroid fine needle aspiration cytology," Diagnostic Cytopathology. 2002; 26(1): 41-44.

18. Conzo G, Calo ` PG, Gambardella C, Tartaglia E, Mauriello C, Della Pietra C, et al: Controversies in the surgical management of thyroid follicular neoplasms. Retrospective analysis of 721 patients. Int. J. Surg. 2014; 12(1): 29-34.

19. Troncone G, Volante $M$, Iaccarino A, Zeppa $P$, Cozzolino I, Malapelle U, et al: Cyclin D1 and D3 overexpression predicts malignant behavior in thyroid fine-needle aspirates suspicious for Hurtle cell neoplasms. Cancer Cytopathol. 2009; 117: 522-529.

20. Cantisani V, Ulisse S, Guaitoli E, De Vito C, Caruso R, Mocini R, et al: Q-elastography in the presurgical diagnosis of thyroid nodules with indeterminate cytology. PLoS One. 2012; 7(11): e50725.

21. Baldini E, Sorrenti S, Di Gioia C, De Vito C, Antonelli A, Gnessi L, et al: Cervical lymph node metastases from thyroid cancer: Does thyroglobulin and calcitonin measurement in fine needle aspirates improve the diagnostic value of cytology? BMC Clin Pathol. 2013; 13: 7.

22. Bellevicine $C$, Vigliar $E$, Malapelle $U$, Pisapia P, Conzo G, Biondi B, Vetrani A, et al: Cytopathologists can reliably perform ultrasound-guided thyroid fine needle aspiration: A 1-year audit on 3715 consecutive cases. Cytopathol. 2016; 27(2), 115-121.

23. De Carvalho GA, Paz-Filho G, Cavalcanti TC, et al: Adequacy and diagnostic accuracy of aspiration vs. capillary fine needle thyroid biopsies. Endocr Pathol. 2009; 20: 204-208.

24. Baloch ZW, LiVolsi VA: Follicular-patterned lesions of the thyroid: the bane of the
150.

25. Richmond BK, O'Brien BA, Mangano W, et al: The impact of implementation of the Bethesda system for reporting thyroid cytopathology on the surgical treatment of thyroid nodules. $\mathbf{A m}$ Surg. 2012; 78: 706-710.

26. Bahar G, Braslavsky D, Shpitzer T, e Coll: The cytological and clinical value of the thyroid "follicular lesion." Am J Otolaryngol. 2003; 24: 217-220.

27. Cetin B, Aslan S, Hatiboglu C, et al: Frozen section in thyroid surgery : Is it a necessity ? $\boldsymbol{J}$ Can Chir. 2004; 47: 29-33.

28. Udelsman R, Westra WH, Donovan PI, Sohn $\mathrm{TA}$, Cameron JL: Randomized prospective evaluation of frozen-section analysis for follicular neoplasms of the thyroid. Ann Surg. 2001; 233: 716-722.

29. Antunes CM, Taveira-Gomes A: Lobectomy in follicular thyroid neoplasms' treatment. Int $\boldsymbol{J}$ Surg. 2013; 11(9): 919-922.

30. Schlinkert RT, Van Heerden JA, Goellner JR, et al: Factors that predict malignant thyroid lesions when fine-needle aspiration is "suspicious for follicular neoplasm". Mayo Clin Proc. 1997; 72: 913-916.

31. Kim ES, Nam-Goong IS, Gong G, et al: Postoperative findings and risk for malignancy in thyroid nodules with cytological diagnosis of the so-called "follicular neoplasm". Korean $J$ Intern Med. 2003; 18: 94-97.

32. Mihai R, Parker AJC, Roskell D, Sadler GP: One in four patients with follicular thyroid citology (THY3) Has a thyroid carcinoma. Thyroid. 2009; 19: 33-37.

33. Condorelli E, Catania A, Sorrenti S: Clinical and ultrasound parameters in the approach to thyroid nodules cytologically classified as indeterminate neoplasm. Diagn Cytopathol. 2009; 37: 783-785.

34. Trimboli P, Ulisse $S$, D'Alò M, Solari F, Fumarola A, Ruggieri $M$, et al: Analysis of clinical, ultrasound and colour flow-Doppler characteristics in predicting malignancy in follicular thyroid neoplasm. Clin Endocrinol. 2008; 69: 342-344.

35. Gulcelik NE, Gulcelik MA, Kuru B: Risk of malignancy in patients with follicular neoplasm: predictive value of clinical and ultrasonographic 
features. Arch Otolaryngol Head Neck Surg. 2008; 134(12):1312-1315.

36. Sorrenti S, Trimboli $P$, Catania A, Ulisse $S$, De Antoni $E$, D'Armiento M: Comparison of malignancy rate in thyroid nodules with cytology of indeterminate follicular or indeterminate hürthle cell neoplasm. Thyroid. 2009, 19: 355360.

37. Tutuncu $Y$, Berker $D$, Isik $S, A k b a b a ~ G, ~ O z u g u z ~ U$, Kucukler FK, et al: The frequency of malignancy and the relationship between malignancy and ultrasonographic features of thyroid nodules with indeterminate cytology. Endocrine. 2014; 45(1):37-45.

38. Calò PG, Medas F, Cruz RS, Podda F, Erdas E, et al: Follicular nodules (Thy3) of the thyroid: is total thyroidectomy the best option? $\boldsymbol{B M C}$ Surgery. 2014; 14:12.

39. Rosato L, Avenia N, Bernante $\mathrm{P}$, et al: Complications of thyroid surgery: analysis of a multicentric study on 14,934 patients operated on in Italy over 5 years. World J Surg. 2004; 28:
271- 276.

40. Wiseman SM, Baliski $C$, Irvine $R$, Anderson D, Wilkins G, et al: Hemithyroidectomy: The optimal initial surgical approach for individuals undergoing surgery for a cytological diagnosis of follicular neoplasm. Ann Surg Oncol. 2006; 13: 425-432.

41. Farkas EA, King TA, Bolton JS, Fuhrman GM: A comparison of total thyroidectomy and lobectomy in the treatment of dominant thyroid nodules. Am Surg. 2002; 68: 678-682.

42. Dobrinja C, Trevisan G, Piscopello L, Fava M, Liguori G: Comparison between thyroidectomy and hemithyroidectomy in treatment of single thyroid nodules identified as indeterminate follicular lesions by fine-needle aspiration cytology. Ann. Ital. Chir. 2010; 81: 403-410.

43. Cooper DS, Doherty GM, Haugen BR, Kloos RT, Lee SL, et al: Revised American Thyroid Association management guidelines for patients with thyroid nodules and differentiated thyroid cancer. Thyroid. 2009; 19: 1167-1214. 